\title{
EVASÃO ESCOLAR NO CURSO DE EDUCAÇÃO FÍSICA DA UNIVERSIDADE FEDERAL DO PIAUÍ
}

\author{
Francisca Islandia Cardoso da Silva* \\ Janete De PÁscoa Rodrigues** \\ Ahecio Kleber Araújo Brito*** \\ Nanci Maria de FrançA****
}

Recebido: 03 jun. 2011

Aprovado: 01 dez. 2012

\begin{abstract}
*Graduada em Licenciatura Plena em Educação Física pela Universidade Federal do Piauí. Educadora Física da Fundação Municipal de Saúde de Teresina. Teresina, PI. E-mail: islandiacardoso@hotmail.com **Doutora em Ciências da Comunicação pela Universidade do Vale do Rio dos Sinos. Professora Adjunta da Universidade Federal do Piauí. Teresina, PI. E-mail: janetepascoa@yahoo.com.br

*** Mestre em Educação pela Universidade Federal do Piauí. Professor Adjunto da Universidade Federal do Piauí. Teresina, PI. E-mail: ahecio@ig.com.br

**** Doutora em Educação Física. Professora do Programa de Pós Graduação Stricto Sensu em Educação Física da Universidade Católica de Brasília. Brasília, D.F. E-mail: mnfranca@terra.com.br
\end{abstract}

Resumo: O presente estudo teve como objetivo investigar os fatores que motivaram a evasão de alunos ingressantes em 2005 no curso de Licenciatura Plena em Educação Física da Universidade Federal do Piauí. Inicialmente, utilizaram-se informações (nome, contato telefônico, período de egressão e endereço) fornecidas pela coordenação do curso a cerca dos 66 alunos ingressantes em 2005 via vestibular. Os demais dados, pessoais e acadêmicos, foram coletados mediante a aplicação de questionários junto aos alunos diplomados em tempo ideal e aos alunos declarados evadidos do curso. A amostra foi composta por 10 alunos diplomados e 11 alunos evadidos. A pesquisa empírica foi realizada no período de agosto a novembro de 2010. Os resultados da pesquisa revelaram que os fatores responsáveis pela evasão dos alunos foram: falta de informações sobre o curso, descontentamento com a profissão, imaturidade ao escolher o curso, pouca interação com o curso, e, simultaneidade de dois cursos. Verificou-se três situações distintas que circundam o processo de evasão do aluno. A primeira é caracterizada pelo abandono do curso de Educação Física para concluir um segundo curso já iniciado; a segunda consiste no abandono do curso para iniciar outro; e a terceira situação caracteriza-se pela evasão total do ensino superior. Conclui-se como principal fator responsável pela evasão do grupo de alunos avaliado, a escolha do curso de maneira equivocada e precipitada por parte do aluno.

Palavras-chave: Ensino superior. Evasão. Educação Física.

\section{DESERTION IN A PHYSICAL EDUCATION PROGRAM AT THE FEDERAL UNIVERSITY OF PIAUÍ}

Abstract: This study aimed to investigate the factors that led to the desertion of new students in 2005 from the undergraduate Physical Education program at the Federal University of Piauí. Initially, we used information (name, phone contact, time of desertion and address) provided by the coordination of the program of about 66 freshmen of the year 2005. Other data, personal and academic, were collected through questionnaires to graduates in optimal time and to students who declared themselves as dropouts. The sample consisted of 10 graduates and 11 dropouts. The empirical research was conducted between August and November 2010. The survey results showed that the factors responsible for student desertion were: lack of information about the program, dissatisfaction with the profession, immaturity in choosing the program, little interaction with the program, and simultaneity of two programs. There are three distinct situations that surround the process of student desertion. The first is characterized by the abandonment of the Physical Education program in order to complete a second program the student has already started and the second is the 
abandonment of the program to start another, and in the third situation students simple abandon higher education. It was concluded that the main reason students of the group evaluated drop out of the program is the wrong and hurried choice they made

Key words: Higher education. Attrition. Physical Education.

\section{INTRODUÇÃO}

A Universidade Federal do Piauí (UFPI), criada através da Lei Federal ${ }^{\circ}$ 5.518, de 12 de novembro de 1968, conta atualmente com 97 cursos de graduação presencial, entre eles Licenciatura Plena em Educação Física desde o ano de 1977. Houve um aumento de vagas na graduação presencial, passando de 2.345 vagas, em 2004, para 5.786 vagas para ingresso em 2010, correspondendo a um acréscimo de 246,74\%. No entanto, observa-se que parte dos alunos do curso de Educação Física da UFPI desliga-se definitivamente do curso antes de integralizá-lo.

Gaioso (2005) destaca dois desafios importantes para quem pretende continuar os estudos em nível acadêmico: a barreira do exame de entrada e os obstáculos, de natureza variada, que surgem ao longo do curso e que por vezes acabam interferindo na continuidade do processo, ocasionando a retenção ou a evasão do estudante de ensino superior.

O Relatório do MEC/INEP (BRASIL, 2009) revelou que no ano de 2008 o percentual de concluintes em relação aos ingressantes de 2005 foi de 57,3\%. Esse fato, geralmente, está associado à retenção, evasão e mobilidade dos estudantes entre instituições e cursos. A evasão é indicativa de falhas no processo de ensino e ineficácia do serviço prestado, além de um aumento nos gastos financeiros, pois a mesma estrutura acadêmica que deveria atender determinado grupo inicial estaria sendo destinada a um quantitativo menor de alunos (MOISÉS FILHO, 2006).

A evasão possui efeitos danosos principalmente para a sociedade, tais como: desperdício de capacidade voltada à formação e capacitação, menor eficiência produtiva das empresas, perda de competitividade nacional e carência de mão de obra especializada (SILVA FILHO et al, 2007). Além disso, a educação constitui o alicerce para que os indivíduos propiciem as verdadeiras mudanças sociais necessárias à melhoria da qualidade de vida e progresso da nação (GAIOSO, 2005). Kipnis (2000) aponta que os estudantes desistentes consideram a evasão como o próprio insucesso em alcançar os objetivos almejados ao ingressar na instituição, além de, causar prejuízos financeiros. 
Pesquisas e informações produzidas acerca do processo de evasão geram subsídios que contribuem para sua compreensão e que podem ser utilizados pelas universidades com a finalidade de melhorar o projeto pedagógico, o currículo e criar programas que auxiliem as necessidades dos estudantes (SCALI, 2009). Grande parte dos estudos brasileiros a respeito desse problema, porém, se limita a análises quantitativas que necessitam ser subsidiadas por informações que o qualifiquem efetivamente, contribuindo para melhor entendimento dos dados (BRASIL.MEC/SESu, 1997, SILVA FILHO et al, 2007).

São diversas as razões para a evasão no ensino superior. Estas variam conforme aspectos de cada curso, contudo, estão atrelados a fatores relacionados às características individuais do estudante, e, fatores internos e externos à instituição. Se por um lado, a evasão procede de uma decisão do aluno, tomada com base em motivos pessoais, por outro lado, ela pode ser resultante de uma união de fatores acadêmicos, socioeconômicos e pessoais, assinalando, nesse caso, mais como exclusão do que propriamente como evasão (BRAGA; PEIXOTO; BOGUTCHI, 2003).

O objetivo desta pesquisa foi investigar os fatores responsáveis pela evasão dos alunos do curso de Licenciatura em Educação Física da UFPI ingressos no ano de 2005 via vestibular.

\section{PROCEDIMENTOS METODOLÓGICOS}

O presente estudo constituiu-se numa perspectiva qualitativa, com emprego do método descritivo.

Inicialmente, foram levantadas informações junto à Coordenação do curso de Licenciatura em Educação Física da UFPI sobre a quantidade de alunos ingressos no ano de 2005, como também o número de alunos desligados da instituição (evadidos) e de diplomados até o momento presente. A coordenação do curso forneceu ainda os possíveis contatos dos alunos de ambos os grupos. De posse destes documentos, foi possível fazer um mapeamento da trajetória escolar desses indivíduos e estimar as taxas de diplomação e evasão considerando-se o ano de ingresso.

Utilizou-se a técnica de amostragem por tipicidade e voluntária que, segundo Marconi; Lakatos (2009, p. 39) é um método não probabilista e ocorre quando o pesquisador busca por uma amostra representativa, "um subgrupo que seja típico em relação à população como um todo”. Os alunos ingressantes em 2005 foram previamente contatados e convidados a participar do estudo. Dentre os 66 alunos, 21 concordaram em participar deste estudo. Os indivíduos foram 
divididos em dois grupos amostrais, conforme sua trajetória escolar: a) grupo 1 - alunos diplomados $(n=10)$; b) grupo 2 - alunos evadidos $(n=11)$.

Foram considerados como alunos evadidos nesta investigação, aqueles ingressos em 2005 que afirmaram não ter qualquer interesse em concluir o curso de Educação Física na UFPI, incluindo-se os casos de transferências internas para outros cursos. Os alunos considerados diplomados em tempo ideal foram aqueles que concluíram o curso em quatro anos ininterruptos. Estes foram incorporados à pesquisa pelas possibilidades de análises comparativas que ofereciam em relação ao grupo de alunos evadidos.

O instrumento usado para coleta de dados consistiu na aplicação de questionários mistos (contendo perguntas abertas e fechadas) junto aos alunos que concordaram em participar do estudo. Os questionários foram elaborados especificamente para cada grupo de indivíduos (diplomados e evadidos), contendo questões relacionadas à sua situação acadêmica e ao seu perfil pessoal, com a finalidade de viabilizar o conhecimento dos fatores intervenientes no processo de evasão e de diplomação dos alunos em estudo.

Os alunos participantes do estudo receberam os questionários via internet (e-mail) e retornaram pelo mesmo meio. Além do questionário, cada indivíduo recebeu um Termo de Livre Esclarecimento sobre a pesquisa e garantia de preservação da identidade, bem como informações sobre o prazo para entrega do questionário respondido.

Os dados coletados foram processados através do programa Microsoft Office Excel 2007, onde se realizou também em alguns momentos da investigação uma análise estatística dos resultados. Isto se deve ao fato de nossa preocupação em descrever, analisar e interpretar os dados coletados por meio dos questionários aplicados junto aos sujeitos da pesquisa.

\section{RESULTADOS E DISCUSSÃO}

As taxas de diplomação e evasão do curso de Educação Física da UFPI no ano-base de 2005 correspondem respectivamente a $28,8 \%$ e $48,5 \%$. Segundo estudo do INEP (2006 apud SILVA FILHO et al, 2007), os cursos de Licenciatura em Educação Física no Brasil, no período entre 2000 e 2005, obtiveram taxa média de evasão igual a 31\%. A evasão anual média entre 2000 e 2005 nas IES públicas oscilou em torno dos $12 \%$ enquanto a taxa nacional típica - IES públicas e privadas - foi de 22\% (SILVA FILHO et al, 2007). Frente a isso, verificou-se que o curso de Educação Física da UFPI no período investigado apresentou uma taxa de evasão superior à média nacional. 


\section{TABELA 1 - Perfil dos alunos diplomados e evadidos do curso de educação física da UFPI}

\begin{tabular}{ccc}
\hline \multirow{2}{*}{ Variáveis } & Diplomados & Evadidos \\
\cline { 2 - 3 } & $\%$ & $\%$ \\
\hline Sexo & & \\
\hline Feminino & $68,4 \%$ & $46,9 \%$ \\
Masculino & $31,6 \%$ & $53,1 \%$ \\
\hline Renda Familiar & & \\
\hline Até 2 salários mínimos & $10 \%$ & $27,3 \%$ \\
3 a 6 salários mínimos 10 salários mínimos & $20 \%$ & $9,1 \%$ \\
Mais que 10 salários mínimos & $10 \%$ & $63,6 \%$ \\
\hline Atividade profissional durante o curso & $60 \%$ & \\
\hline Sim & & $81,8 \%$ \\
Não & $70 \%$ & $18,2 \%$ \\
\hline
\end{tabular}

Fonte: elaborado pelos autores.

No que diz respeito ao sexo, $68,42 \%$ dos alunos diplomados em tempo ideal são do sexo feminino, enquanto que $53,1 \%$ dos alunos evadidos são do sexo masculino. Neste aspecto, alguns estudos como o de Amidani (2004) sobre a evasão no curso de Licenciatura em Matemática da Universidade Federal Fluminense, também observaram que a maioria dos alunos evadidos foi do sexo masculino (56,3\%).

Verificou-se ainda que apenas $10 \%$ dos alunos diplomados participantes da pesquisa fizeram outro curso superior concomitantemente ao curso de Educação Física da UFPI, resultado diferente do encontrado junto ao grupo de alunos evadidos, onde 81,8\% desses alunos realizaram outro curso de forma simultânea ao de educação física na UFPI. Dentre os alunos evadidos, 45,4\% iniciaram outro curso superior simultaneamente ao curso de Educação Física, abandonando o último para dedicarem-se integralmente ao primeiro; 36,4\% abandonaram o curso de Educação Física e, em seguida, ingressaram em outro curso superior; e, 18,2\% evadiram do ensino superior até a data de aplicação do questionário. Com base nesses resultados verificou-se três situações distintas. A primeira é caracterizada pelo abandono do curso de educação física para concluir um 
segundo curso já iniciado. A segunda situação consiste no abandono do curso de educação física para iniciar um outro curso superior, e a terceira situação caracteriza-se pela evasão total do ensino superior, ou seja, o aluno abandonou não somente o curso de educação física, mas o ideal de obter uma formação em nível superior em qualquer área.

Quanto à renda familiar mensal dos alunos estudados, verificou-se que $63,6 \%$ dos alunos evadidos e $60 \%$ dos alunos diplomados possuem renda familiar superior a 10 salários mínimos. A grande maioria dos alunos evadidos exerceu atividade profissional remunerada enquanto realizava o curso de educação física (81,8\%). Não obstante, apenas 9,1\% atribuem o abandono do curso de educação física ao fato de ter que conciliar as atividades profissionais com os estudos.

Alguns estudiosos da área alertam para a necessidade do aluno estabelecer um vínculo com a instituição - integração acadêmica, pois o risco dele se decepcionar com as condições gerais da Universidade, com a qualidade do curso, com os procedimentos didático-pedagógicos ou com a qualificação dos docentes, poderá acarretar em evasão. Ao optar por determinado curso em uma determinada instituição, o aluno é o cliente e a avaliação que ele fará dependerá da comparação entre os serviços recebidos e os esperados previamente (GAIOSO, 2005, PEREIRA, 2003, BIAZUS, 2004). Neste estudo com os alunos do curso de Educação Física da UFPI, 45,4\% dos alunos evadidos e 60\% dos alunos diplomados classificaram a Universidade Federal do Piauí como uma instituição de nível regular; 27,3\% dos evadidos e 70\% dos diplomados avaliaram-na como ótima, e; 27,3\% dos alunos evadidos consideram a instituição ruim.

Quanto à avaliação do curso de Educação Física ofertado pela UFPI, 72,7\% dos alunos evadidos e $62,5 \%$ dos diplomados classificaram como regular; $27,3 \%$ dos evadidos como ruim, e; 37,5\% dos diplomados avaliaram como ótimo.

Sabe-se que as razões para a escolha do curso exercem forte influência sobre permanência ou desistência do estudante no mesmo. Embora o futuro de uma pessoa não dependa apenas de sua escolha profissional e mesmo sabendo que esta escolha pode ser alterada, as questões vocacionais têm se tornado cada vez mais importantes para os indivíduos, pois a escolha envolve perdas, mudanças, medo do fracasso e conflitos (BARDAGI; LASSANCE; PARADISO, 2003).

Gaioso (2005) afirma que em alguns casos, o desejo de ter um título de nível superior pode levar os candidatos a procurarem cursos menos concorridos. $\mathrm{O}$ Gráfico 1 mostra os motivos dos alunos diplomados para a escolha do curso de Educação Física na UFPI. 


\section{FIGURA 1 - Motivos apontados pelos alunos diplomados para escolha do curso.}

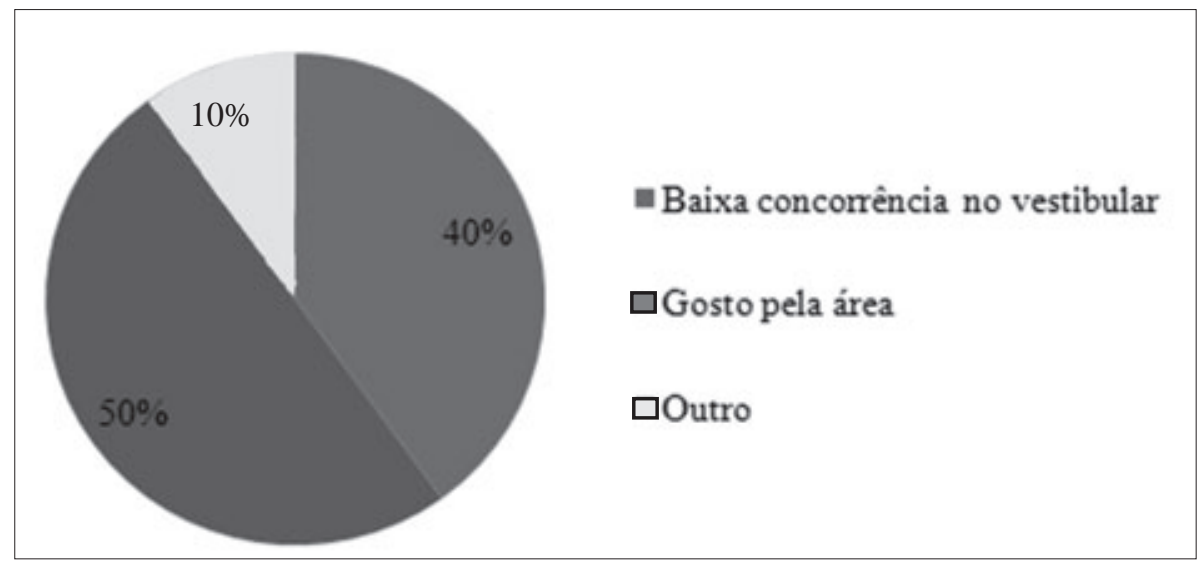

Fonte: elaborado pelos autores.

A UFPI permite que o candidato no ato da inscrição preste vestibular para dois cursos diferentes - primeira e segunda opção. Caso o estudante não consiga ingressar na primeira opção, ainda pode conquistar uma vaga na segunda opção de curso. Conforme demonstra a Tabela 2, a maior parte dos alunos evadidos afirma que ingressaram no curso de educação física da UFPI pelo fato de não terem conseguido ingressar em outros cursos, ou seja, restou-lhes a segunda opção de inscrição no vestibular - educação física.

TABELA 2 - Motivos citados pelos alunos evadidos, ingressos em 2005, para escolha do curso de educação física da UFPI.

\begin{tabular}{lcc}
\hline \multicolumn{1}{c}{ Motivos } & Frequência & $\%$ \\
\hline Não conseguiu ingressar em outro curso superior & 5 & $45,4 \%$ \\
Baixa concorrência no vestibular & 1 & $9,1 \%$ \\
Gosto pela área & 4 & $36,4 \%$ \\
Mercado de trabalho (perspectiva salarial) & 1 & $9,1 \%$ \\
\hline
\end{tabular}

Fonte: elaborado pelos autores. 
Para Tinto e Pusser (2006), o apoio mútuo entre colegas favorece a obtenção de melhores resultados e uma maior motivação para a conclusão do curso. No presente estudo, $80 \%$ dos alunos diplomados disseram que mantinham uma boa relação com os colegas de curso. Dentre os evadidos, 72,8\% mantinham um relacionamento bom ou ótimo com os colegas de curso.

Também a relação professor-aluno é fundamental para manutenção do aluno no curso, uma vez que o processo ensino-aprendizagem é baseado na interação professor/aluno/meio. O professor pode fazer a diferença na vida acadêmica e profissional de um aluno. Nesse estudo, $80 \%$ dos alunos diplomados e $46 \%$ dos alunos evadidos julgaram como boa a sua relação com os professores.

Questionados sobre as estratégias metodológicas adotadas para estudar, os alunos evadidos citaram: (i) anotações durante a aula; (ii) leitura de livros e artigos, e; (iii) construção de resumos dos conteúdos. Além dessas estratégias, os alunos diplomados citaram também a reserva de tempo diário (média de três horas) somente para estudos, fator ignorado pelos alunos evadidos.

No que diz respeito ao rendimento dos alunos junto ao curso, $60 \%$ dos alunos diplomados e 63,6\% dos alunos evadidos disseram não ter sofrido reprovações em disciplinas durante o curso. Isto implica dizer que os motivos para evasão dos alunos do curso de educação física da UFPI não estão associados a reprovações em disciplinas durante o curso.

Os alunos diplomados atribuíram à UFPI a responsabilidade pela conclusão do curso e elogiaram a estrutura física da instituição, o acervo bibliográfico e o quadro de professores. Apenas 36,4\% dos alunos evadidos responsabilizaram a instituição UFPI pela sua evasão e usaram como justificativas: (i) o quadro ruim de professores; (ii) o funcionamento em turno integral do curso, e; (iii) a péssima infraestrutura da instituição. Porém, os alunos que isentaram a UFPI da responsabilidade (63,6\%), elogiaram o corpo discente e a infraestrutura da IES e assumiram a responsabilidade pela ausência de dedicação adequada ao curso.

As dificuldades de adaptação ao curso e à instituição, a falta de clareza das perspectivas de formação profissional, a baixa atratividade profissional, a inadequação curricular, a metodologia didático-pedagógica, além de outras situações, implicam em uma responsabilidade da instituição no desencadeamento do processo de desligamento ou retenção de alguns estudantes (ADACHI, 2009).

Quando questionados sobre os motivos que levaram os alunos a abandonarem o curso de educação física, estes relataram fatores como decepção com o curso, baixa expectativa de remuneração profissional, realização de outro curso concomitante ao de Educação Física, exercer atividade remunerada no turno das aulas. 
TABELA 3 - Motivos citados pelos alunos evadidos, ingressos em 2005, para não concluir o curso de educação física

\begin{tabular}{lcc}
\hline \multicolumn{1}{c}{ Motivo } & $\begin{array}{c}\text { Frequên- } \\
\text { cia }\end{array}$ & $\%$ \\
\hline Decepção com o curso & 5 & $45,4 \%$ \\
Baixa expectativa profissional (remuneração) & 1 & $9,1 \%$ \\
Realização de outro curso concomitante ao de Educação Física & 4 & $36,7 \%$ \\
Exerce atividade remunerada no turno das aulas & 1 & $9,1 \%$ \\
\hline
\end{tabular}

Fonte: elaborado pelos autores.

Dentre os alunos evadidos, 27,3\% desligaram-se do curso antes de iniciarem o quarto período, e 72,7\% desistiram a partir do início do quarto período. Lehman (2005) constatou em seu estudo que as desistências ocorrentes antes do quarto período do curso superior estão condicionadas diretamente à escolha do curso e à dificuldade de adaptação à vida acadêmica. Já a evasão a partir do quarto período, ocorre devido ao questionamento dos estudantes sobre o sentido da profissão escolhida e o atendimento às suas expectativas.

Segundo um estudo realizado pelo MEC/SESu (BRASIL,1997), a escolha da profissão é influenciada por fatores externos, tais como: o prestígio social da profissão, as possibilidades de desenvolvimento profissional, mercado de trabalho as expectativas de remuneração. A falta de informações sobre a futura profissão é um dos entraves para a diplomação do aluno no curso superior, pois quando eles percebem que foram movidos por expectativas infundadas a respeito da profissão escolhida, decepcionam-se, sentem-se desestimulados e passam a ter dúvidas quanto à sua formação, o que pode acarretar em retenção ou evasão.

No caso dos cursos de Licenciatura em geral a situação é ainda pior uma vez que sua desvalorização social é histórica. O status profissional ansiado pelo estudante, mesmo aquele que diz ter vocação para determinada profissão, compreende aspectos relacionados com a valorização social e pessoal da carreira escolhida.

Neste sentido, buscou-se levantar algumas sugestões junto aos alunos evadidos pesquisados, sobre medidas necessárias para reduzir a taxa de evasão do curso de Educação Física na UFPI, dentre as quais podemos destacar: Melhorias na infraestrutura da instituição; capacitação e qualificação do corpo docente; redução da burocracia para resolução de problemas do corpo discente; 
promoção de eventos que integrem e mostrem a relevância do profissional de Educação Física para a sociedade; incentivo aos alunos com aumento das bolsas de iniciação científica, monitoria e cursos de extensão.

\section{CONSIDERAÇÕES FINAIS}

A evasão no ensino superior está relacionada entre outros ao nível de satisfação dos alunos com a instituição, ao curso e à carreira escolhidos. Este estudo não sugere que uma IES tenha seu desempenho avaliado somente pelo índice de diplomas expedidos, mas que esses índices indiquem se as propostas e sistema de funcionamento da universidade estão atendendo aos anseios de seus atores sociais.

Portanto, pode-se inferir por meio deste estudo, que dentre os motivos de maior representatividade no processo de evasão dos alunos do curso de educação física da UFPI, está a desinformação por parte do aluno sobre o curso. Neste aspecto, estudo do MEC/SESu (BRASIL, 1997, p. 137) afirma que a desinformação e/ou informações distorcidas sobre a profissão e o curso escolhido pode levar os estudantes a desistirem dos cursos ao perceberem que foram movidos por expectativas infundadas a respeito da profissão escolhida.

Outro fator a ser destacado como responsável pela evasão, seria o descontentamento com as perspectivas profissionais. O status profissional ansiado pelo estudante, mesmo aquele que diz ter vocação, compreende aspectos relacionados com o prestígio social da função e a expectativa de remuneração. No caso dos cursos de Licenciatura, o risco de evasão é ainda maior, visto que a desvalorização social desta área é histórica. Quando esses projetos de ascensão social e bons salários não se viabilizam na área escolhida, o aluno tende a abandonar o curso e buscar outro lhe que possa oferecer maior status social e econômico.

Para suprir a incerteza produzida pelo quadro de situações acima, os alunos optam pela realização de dois cursos simultaneamente, sendo o segundo curso aquele considerado como de maior prestígio social (fisioterapia, enfermagem, medicina, direito, entre outros). Essa ocorrência leva, geralmente, ao abandono do curso de licenciatura.

É notório que questões relacionadas a preconceitos que permeiam historicamente o cenário das profissões parecem marcar ainda hoje a trajetória dos cursos e dos profissionais no Brasil. Trabalhadores que não atuam em áreas consideradas e seguidas pelas classes dominantes no Brasil desde o período colonial, tais como medicina, direito, engenharias e outras, parecem sofrer ainda na contemporaneidade com discriminações que resultam em baixos salários, 
baixa autoestima dos profissionais, e na exclusão dessas atividades do rol das profissões vistas como "importantes" para a sociedade.

Se os profissionais da área da educação são concebidos por muitos como profissionais de "segunda linha", o que dizer sobre os profissionais de Educação Física que aglutinam além dos estigmas já mencionados da área pedagógica, rótulos como, "profissionais não pensantes" e "supérfluos" no mercado de trabalho em nosso país.

Ao mesmo tempo em que é atribuído ao professor o poder de solucionar todas as mazelas do ensino no contexto nacional, é conferida a ele a "culpa" pela atual situação do sistema de ensino público no país, e isso acarreta uma desqualificação do trabalho docente. Porém, a qualidade do ensino só ocorrerá se houver a valorização do magistério e, esta última, como afirma Oliveira (2009, p. 2) só será obtida se houver uma política pública global que considere a formação inicial e continuada, as condições de trabalho, salário e carreira de nossos professores.

\section{REFERÊNCIAS}

\section{ADACHI, A. M. C. T. Evasão e evadidos nos cursos de graduação} da Universidade Federal de Minas Gerais. 2009. 214 p. Dissertação (Mestrado em Educação) - Universidade Federal de Minas Gerais, Belo Horizonte, 2009.

AMIDANI, C. Evasão no ensino superior a distância: o curso de Licenciatura em Matemática a distância da Universidade Federal Fluminense/CEDERJ - RJ. 2004. 182 p. Dissertação (Mestrado em Educação) - Universidade de Brasília, Brasília, 2004.

BARDAGI, M. P.; LASSANCE, M. C. P.; PARADISO, A. C. Trajetória acadêmica e satisfação com a escolha profissional de universitários em meio de curso. Revista Brasileira de Orientação Profissional, São Paulo, v. 4, n. 1, p. 153-166, 2003.

BIAZUS, C. A. Sistema de fatores que influenciam o aluno a evadirse dos cursos de graduação na UFSM e na UFSC: um estudo no curso de Ciências Contábeis. 2004. 203 p. Tese (Doutorado em Engenharia de Produção) - Universidade Federal de Santa Catarina, Florianópolis, 2004. 
BRAGA, M. M.; PEIXOTO, M. C. L.; BOGUTCHI, T. F. A evasão no ensino superior brasileiro: o caso da UFMG. Avaliação, Campinas; Sorocaba, v. 8, n. 3, p. 161-189, jul/set. 2003.

BRASIL.MEC/INEP. Censo da Educação Superior 2008 (Dados preliminares), 2009. Disponível em: <http://www.inep.gov.br/download/ censo/2008/resumo_tecnico_2008_15_12_09.pdf>. Acesso em: 15 ago. 2010.

BRASIL.MEC/SESu. Diplomação, retenção e evasão nos cursos de graduação em instituições de ensino superior públicas, 1997. Disponível em: <http://www.ebah.com.br/diplomacao-retencao-e-evasao-nos-cursosde-graduacao-em-instituicoes-de-ensino-superior-publicas-1173947.html>. Acesso em: 01 jun. 2009.

\section{GAIOSO, N. P. L. O fenômeno da evasão escolar na educação superior} no Brasil. Universidade Católica de Brasília, 2005. Disponível em: $<$ http://proyecto.unlam.edu.ar/espec/htdocs1/\%5Cprogramas\%5CDese rci\%C3\%B3n\%5CInforme\%20Deserci\%C3\%B3n\%20Brasil\%20-\%20 D\%C3\%A9bora\%20Niquini.pdf >. Acesso em: 20 out. 2010.

KIPNIS, B. A pesquisa institucional e a educação superior brasileira: um estudo de caso longitudinal da evasão. Linhas Críticas, Brasília, v. 6, n. 11, p. 17- 32, jul./dez. 2000.

LEHMAN, Y. P. Estudo sobre evasão universitária: as mudanças de paradigma na educação e suas consequências. São Paulo, 2005. 235 p. Tese (Livre-docência em Psicologia Social) - Universidade de São Paulo, São Paulo, 2005.

MARCONI, M. A.; LAKATOS, E. M. Técnicas de pesquisa: planejamento e execução de pesquisas, amostragens e técnicas de pesquisa, elaboração análise e interpretação de dados. 7. ed. São Paulo: Atlas, 2009. 277 p.

MOISÉS FILHO, J. G. Qualidade de ensino e eficiência técnica no ensino superior privado: o caso do Distrito Federal. 2006. 164 p. Dissertação (Mestrado em Administração) - Universidade de Brasília, Brasília-DF, 2006.

OLIVEIRA, F. F. A. A formação de professores e a valorização do magistério após a reforma educacional: para onde apontam as pesquisas sobre o tema? In: CONGRESSO NACIONAL DE PSICOLOGIA ESCOLAR 
EVASÃO ESCOLAR NO CURSO DE EDUCAÇÃO FÍSICA DA UNIVERSIDADE FEDERAL DO PIAUÍ

EDUCACIONAL, 9. 2009, São Paulo. Anais eletrônicos... São Paulo: ABRAPEE, 2009. Disponível em: <http://www.abrapee.psc.br/documentos/ cd_ix_conpe/IXCONPE_arquivos/4.pdf >. Acesso em: 12 set. 2011.

PEREIRA, F.C.B. Determinantes da evasão de alunos e os custos ocultos para as instituições de ensino superior. 2003. 173 p. Tese (Doutorado em Engenharia de Produção) - Universidade Federal de Santa Catarina, Florianópolis, 2003.

SCALI, D.F. Evasão nos cursos superiores de tecnologia: a percepção dos estudantes sobre seus determinantes. 2009. 150 p. Dissertação (Mestrado em Educação) - Universidade Estadual de Campinas, Campinas, 2009.

SILVA FILHO, R. L. L. et al. A evasão no ensino superior brasileiro. Cad. Pesq, São Paulo, v. 37, n. 132, p.641-659, set./dez. 2007.

TINTO, V.; PUSSER, B. Moving from theory to action: building a model of institutional action for student success. National Postsecondary Education Cooperative - NPEC, Virginia, 2006. Disponível em: <http://web.ewu.edu/ groups/academicaffairs/IR/NPEC_5_Tinto_Pusser_Report.pdf >. Acesso em: 20 out. 2010. 
